was kept under the influence of opium, and did well for forty. eight hours, when unfavourable symptoms appeared,-namely, tympanitis; vomiting; small, quick, weak pulse; white tongue; thirst, \&c. These symptoms continued, with increased rapidity and feebleness of pulse, and prostration of power, till she sank, about seventy eight hours after the operation.

The necropsy revealed universal peritonitis, of a low form, without any secondary hæmorrhage.

\section{MIDDLESEX HOSPITAL.}

LARGE UNILOCULAR CYST OF THE OVARY; OVARIOTOMY; FATAL RESULT.

(Under the care of Mr. NUNN.)

AMrongst the cases which we place upon record to-day are those of patients at the ages of eighteen, twenty, and thirty years - periods of life that are favourable to operation, if it is done before the disease has become somewhat advanced, and adhesions have formed. There can be no doubt that the best line of practice is an early removal-as soon, in fact, as enlargement of the ovary can be made out; we believe we should then have fewer fatal cases to record. Unfortunately, however, patients will not seek for relief until the tumour has become considerably developed, and in the meantime it will have undergone important changes for the worse. (For the notes of the following case we are indebted to Mr. F. H. Watts, housesurgeon to the hospital.)

H. E- aged twenty, servant-maid, was operated on by Mr. Nunn on Monday, July 30th, $1 \succ 60$, at two P.M.; incision, five inches. The cyst, containing from three to four gallons of a clear, yellow, serous fluid, was generally adherent to the wall of the abdomen, but especially so towards the right side, and also to the lower margin of the great omentum. After drawing out the cyst, a clamp was placed on the pedicle, up to which the wouni was closed by interrupted sutures of iron wire. No considerable hæmorrhage into the cavity of the abdomen was observed. The patient survived until seven A. M. on the Friday following, or eighty-nine hours after the operation.

Persistent vomiting of whatever was taken into the stomach was the chief characteristic of the case; flatulent distension proving, as is usual, one of the greatest causes of distress.

At forty-five minutes past eight P.M., on the 30 th of $\mathrm{July}$, the pulse was 108 ; at midnight, $136 . \quad$ On the 31 st it was 148 ; Aug. 1st, 138; Ang 2nd, 150.

At the post-mortem examination, a large quantity of bloody serum was found in the abdominal cavity, and a coagulum of several ounces in the right hypochondriac and lambar regions, doubtless due to hæmorrhage from an omental artery. There were but slight traces of adhesive peritonitis, and fewer of reparative action at the wound in the abdominal parietes, or of inflammatory action at the point of application of the clamp to the pedicle, or, in other words, to the broad ligament of the uterus.

The symptoms of peritonitis were not distinetly manifest until the 2nd of August, when the pain and tenderness of the abdomen became more deciled, and distension began to take place. On the day preceding, considerable hopes of recovery were entertained.

\section{LONDON HOSPITAL.}

MULTILOCULAR OVARIAN CYST OF VERY LARGE SIZE; OVARIOTOMY ; FATAL RESULT.

(Under the care of Mr. Curling.)

TH: patient was a well-nourished girl, eighteen years of age, who was sent up from the country to Mr. Curling, for the purpose of undergoing an operation for the removal of an ovarian tumour. She had been tapped three times in quick succession, and on her admission in to the hospital the abdomen was enormously enlarged. The tumour was first noticed three years before. Since her arrival in London, it was found to be polycystic; all relief by tapping, therefore, was illusory. The tumour involved the left ovary, and had so distended the abdo. men as to push up the thoracic viscera and project the lower ribs. Externally several broad grooves were observed, indi- cating the divisions of the cysts. The character of the tumour, its large size and rapid increase, showed its unfavourable nature, and that life could be prolonged but a few months. After consultation with his colleagues, therefore, Mr. Curling determined to perform ovariotomy.

The operation was performed on the 24 th of February, 1860, when the patient was under the influence of chloroform, in a private ward, previously well heated. The abdomen was laid open from the umbilicus to within a hand's-breadth of the pubes, and subsequently the incision was prolonged two inches further upwards. Very extensive and firm bands of adhesion united the tumour to the anterior and lateral parietes of the abdomen. These were carefully broken through, but much force was necessary to do this. The omentum was adherent to the upper part, and three ligatures were applied before division. Not less than a dozen large cysts, filled with a thick, viscid fluid, of various colours, were evacuated before the tumour was sufficiently diminished to allow of its passing through the in. cision. The pedicle was broad, and a clamp was securely applied, without any undue traction on the uterus, \&c. The operation, although prolonged, was almost a bloodless one. The wound was closed by deep sutures of silk and of wire alternately, and the ligatures applied to the omentum were all secured, so that the tied parts were external to the peritoneum. She was quiet after the operation, with a good pnlse and aspect. She passed a comfortable evening, and slept fairly through the night. In the morning, she complained of distressing thirst, and was restless, the skin became hot and dry, the respiration rapid, the pulse scarcely perceptible, and she died rather suddenly in the afternoon.

At the post-mortem examination, made two days after death by Mr. Griffiths, the house-surgeon, a considerable quantity of blood-stained serum occupied the depending parts of the abdo. minal cavity, but there was no coagulum whatever. The intestines were not distended, and althongh congested, showed no signs of actual peritonitis. The omentum and the parietal peritoneum, where the adhesions had existed, showed, of course, signs of contusion, tearing, \&c., but not at all more than was expected. The remaining organs were all healthy.

\section{Attevical Socicties.}

\section{PATHOLOGICAL SOCIETY OF LONDON. \\ Mr. FergusSon, PRESTDENT. \\ TUESDAY, JAN. 1ST, 1561.}

THE minutes of the last meeting were read and confirmed.

The financial statement and annual report were read by the Hon. Surgical Secretary, Mr. Thompson.

It was proposed by Mr. Brooke, and seconded by Dr. GIBB, -" That the report read be received and adopted." Carried unanimously.

TUMOURS INVOLVING THE RECTUM AND ADJACENT PARTS.

Dr. Schulhof exhibited this case. He believed it to be an example of malignant disease. It was remarkable that very little pain had been suffered by the subject of it.

Mr. Asuron regarded it as an example of cancer of the rectum; such cases are common. He had observed them sometimes associated with very little pain, diarrhoea being the main symptom existing for a considerable time. Vomiting did not usually occur unless there was occlnsion. In answer to a question from Dr. Schulhof, he might state that, unless the disease very largely affected the bladder, urinary symptoms were not often present.

Mr. ADAMS and others entered on the discussion.

The Prusident confirmed Mr. Ashtou's experience respecting the painlessuess of some examples of malignant disease of the rectum.

Mr. Prescotr Hewert stated, that this character was observed in the last instance he was called upon to examine, and gave interesting details of it at some length. Six weeks of absolute constipation had preceded death, occurring from the occlusion of the bowel. Fecal matter had escaped from the bowel into the peritoneal cavity for some time before death. This very remarkable occurrence had been witnessed by the speaker on one occasion previously.

INTUSSUSCEPTION IN TH HORSE.

Dr. GIBB presented this specimen for Mr. Curran. The animal was a small black horse, who exhibited suddenly severe 